Egyptian Journal of Rabbit Science, 26(2): 255-265 (2016)

\title{
FORMATION RATE AND CELLULAR COUNT OF BLASTOCYSTS OF RABBITS AS AFFECTED BY EPIDERMAL GROWTH FACTOR SUPPLEMENTATION TO CULTURE MEDIUM OF FRESH OR VITRIFIED MORULAE
}

\author{
Y. S. Hussein *, Sara F. Fouda** and I.T.EL-Ratel*** \\ * Animal Production Research Institute, Agricultural Research Center, Egypt. \\ ** Department of Poultry Production, Faculty of Agriculture, Mansoura \\ University, Mansoura, Egypt. \\ **Department of Poultry Production, Faculty of Agriculture, Damietta \\ University, Damietta, Egypt.
}

The aim of this study was to evaluate the effect of addition of epidermal growth factor (EGF) to culture medium of fresh and vitrified rabbit embryos on formation rate into blastocysts/hatched blastocysts and quality of the embryos. Total of 16 mature NZW rabbit does were superovulated by PMSG and hCG. Embryos were recovered 64-66 $h$ post-mating by flushing from the oviducts of the slaughtered animals. Compact morulae were used in this study. Embryos were divided into two groups, fresh $(n=200)$ and intended for vitrification $(n=185)$. Fresh $(n=200)$ or vitrified embryos $(n=150)$ were in vitro cultured. Either fresh or vitrified embryos were in vitro cultured in medium supplemented with EGF ( $n=100$ and 75) as compared to control medium ( $n=100$ and 75$)$, respectively, under mineral oil in $\mathrm{CO}_{2}$ incubator at $38^{\circ} \mathrm{C}$, 95\% humidity and $5 \% \mathrm{CO}_{2}$ in air. Embryos were assessed daily to record the developmental competence of embryos in term of formation rate of embryos at blastocyst from morula stage, from blastocyst to expanded blastocyst stage or from expanded to hatched blastocyst throughout 5 days as culture period. Total cell number and intrazonal diameter of blastocysts were determined. Results showed that formation rate of blastocyst (BLs), expanded BLs and hatched BLs was the highest $(P<0.05)$ for fresh embryos cultured with EGF (86.00, 94.11 and $88.92 \%)$, moderate for fresh embryos without EGF (74.00, 81.11 and $75.23 \%)$ or those vitrified with EGF (70.62, 80.67 and $73.89 \%)$, and the lowest for vitrified embryos cultured without EGF (57.76, 70.00 and 56.76\%). Adding EGF in culture medium increased $(P<0.05)$ total cell number and intrazonal diameter of blastocysts produced from fresh (121.20/BLs and $129.2 \mu \mathrm{m})$ or vitrified (118.2/BLs and 
$124.6 \mu \mathrm{m})$ morulae as compared to fresh (109.0/BLs and $124.2 \mu \mathrm{m})$ or vitrified $(105 / B L s$ and $117.6 \mu \mathrm{m})$ morulae cultured with free media.

In conclusion, supplementation of culture medium with 10 $\mathrm{ng} / \mathrm{ml}$ epidermal growth factor (EGF) had beneficial effects of the developmental competence of fresh or vitrified embryos at morula stage to reach hatched blastocyst stage with good quality.

Keywords: Rabbit, embryo, vitrification, growth factor, development, quality.

Cryopreservation is an important tool for creation of embryo banks for future use in animal breeding. This technique also enables to protect germ cells of rare or endangered species and strains of farm and wild animals. In certain cases optimization of cryopreservation protocols for more sensitive embryos is relevant (Chrenek et al., 2014). Cryobiologist and reproductive biologists have provided with a better understanding of the physical principals of cryopreservation techniques (Liu et al., 2012) and their short and long term biological effects on the embryo. Regardless of embryo production, all unused embryos are cryopreserved by vitrification (Do et al., 2014), which is an important tool for preservation of mammalian embryos (Chrenek and Makarevich. 2011), but require highly trained personnel for manipulating embryos in small volumes and in short equilibration times (Almiñana and Cuello, 2015). In the vitrification process, the embryo is exposed first to a low cryoprotectants (CPAs) concentration solution and then to a much more concentrated solution. Vitrification relies especially on 2 aspects that are closely linked: 1) A very high cooling rate (around $20000^{\circ} \mathrm{C} / \mathrm{min}$ ), which is achieved by plunging the sample in liquid nitrogen $\left(-196^{\circ} \mathrm{C}\right)$ and by using different devices or straws (Arav, 2014) that allow embryo vitrification in minimal volumes; and 2) the high viscosity of vitrification media, which depends on the concentration of the CPAs.

Regardless of the method of freezing employed, the freezing and thawing processes decrease embryo viability, an effect attributed to physical and chemical damage induced during cryopreservation (Bagusi et al., 2000). Despite many reports on successful vitrification of mammalian embryos, the rate of development of vitrified-warmed embryos is still lower than that of non-vitrified embryos (Cseh et al., 1999). On the other hand, as the embryo develops, factors present in medium surrounding the embryo can influence cell growth and development (Díaz-Cueto and Gerton, 2001).

Among the growth factors and receptors, epidermal growth factor (EGF) and insulin-like growth factor-1 (IGF-1) have been shown to enhance blastocyst development (Pan et al., 2105). EGF is a $6 \mathrm{kDa}$ protein consisting 
ORMATION RATE AND CELLULAR COUNT OF BLASTOCYST RABBITS

of 53 amino acid residues and three intra-molecular disulfide bridges such as cell proliferation; promote cell differentiation, steroidogenesis and play a key regulatory role in preimplantation embryonic development (Babitha et al., 2014). The in vitro effects of EGF on embryo development are reported in several mammalian species (Ahumada et al., 2013). In this respect, addition of EGF to culture medium promotes cleavage and blastocyst development and implantation rate after transfer to the uterus, and a deficiency in EGF results in deficiencies in placental structure and fetal growth (Chandra et al., 2012). EGF binds with its receptor (EGFR) to enhance cell proliferation (Fujihara et al., 2014). It has been shown that EGFR is expressed in the 2-cell to blastocyst stage in the mouse and from the 8-cell stage to the blastocyst stage in human (Kane et al., 1997). EGF treatment significantly increased the blastocyst formation rate, the total number of cells per blastocyst, the cell ratio of the inner cell mass and the trophectoderm (Zeng and Harris, 2014).

Therefore, the objective of the present study was to evaluate the effect of adding EGF to culture medium on embryo development, in terms of formation rate of blastocysts / hatched blastocysts and number of cells of blastocyst for vitrified compared with non-vitrified (fresh) rabbit embryos.

\section{MATERIALS AND METHODS}

This study was carried out at the International Livestock Management Training Center (ILMTC), belonging to the Animal Production Research Institute, Agricultural Research Center, Ministry of Agriculture.

\section{Embryos recovery:}

Total of 16 New Zealand White rabbit does (4-5 months of age, 3-3.5 $\mathrm{kg}$ live body weight) were superovulated using a single i.m. injection of $20 \mathrm{IU}$ PMSG/kg LBW (Foligon, Intervet International B.V., Boxmeer), followed by $40 \mathrm{IU}$ hCG/kg LBW (Pregnyl, Organon, Nile Co., Egypt), $48 \mathrm{~h}$ later on day of natural mating with fertile bucks belonging to the same rabbit breed. Embryos were recovered 64-66 h post-mating by flushing from the oviducts of the slaughtered animals using flushing medium, phosphate buffer saline (PBS) supplemented with $10 \%$ fetal calf serum (FCS, sigma) and antibiotics, 100 IU penicillin and $100 \mu \mathrm{g} / \mathrm{ml}$ streptomycin (Sigma Chemical Co., St. Louis, Mo, USA) in Petri dishes. All recovered embryos were evaluated morphologically under inverted microscope and normal embryos (compact morula with intact mucin coat and zona pellucida were used in this study according to Mehaisen et al. (2015). Embryos were washed twice in fresh flushing medium and randomly divided into two groups, fresh $(\mathrm{n}=200)$ and intended for vitrification $(\mathrm{n}=185)$. 


\section{Embryo vitrification and thawing procedures:}

The vitrification of embryos was performed following the method developed by Mehaisen et al. (2006) with minor modifications. Briefly, the vitrification procedure was carried out in two steps at $25^{\circ} \mathrm{C}$. In the $1^{\text {st }}$ step, embryos were placed for $2 \mathrm{~min}$ in a vitrification solution consisting of $12.5 \%$ (v/v) dimethyl sulphoxide (1.75 M DMSO, Sigma) and $12.5 \%$ (v/v) ethylene glycol (2.23 M EG, Sigma) in DPBS supplemented with $10 \%$ (v/v) of FCS. In the $2^{\text {nd }}$ step, embryos were suspended for $1 \mathrm{~min}$ in a solution of $20 \%$ (v/v) DMSO and 20\% (v/v) EG in DPBS supplemented with 10\% (v/v) of FCS. Then, embryos suspended in vitrification medium were loaded into $0.25 \mathrm{ml}$ plastic straws (IMV, L'Aigle, France) between two drops of DPBS separated by air bubbles. Finally, the straws were sealed and plunged directly into liquid nitrogen.

After storage in liquid nitrogen for more than one week, straws were warmed up in $25^{\circ} \mathrm{C}$ water-bath for $10-15 \mathrm{sec}$. Then the content of the straw was expelled into an empty Petri dish and mixed by gently shaking the dish. The embryos were transferred to $0.5 \mathrm{M}$ sucrose solution (S-PBS) for $5 \mathrm{~min}$ and then to $0.25 \mathrm{M}$ sucrose solution (0.5 S-PBS) for $5 \mathrm{~min}$ and washed twice in DPBS supplemented with 20\% FCS (Celestinos and Gatica, 2008).

\section{Treatment and embryo culture:}

Culture medium was tissue culture medium (TCM-199, Sigma) supplemented with $4 \mathrm{mg} / \mathrm{ml}$ bovine serum albumin (BSA, Sigma) and 50 $\mu \mathrm{g} / \mathrm{ml}$ of Gentamicin sulphate. Two types of culture medium were used in this study for in vitro culture of embryos. These types included culture medium supplemented with $10 \mathrm{ng} / \mathrm{ml}$ epidermal growth factor (EGF, Sigma) as compared to control culture medium without supplementation).

Fresh $(n=200)$ or vitrified embryos (Survival viable, $n=150)$ were in vitro cultured in a one-well embryo culture dish (NUNC A/ S, Thermo Fischer Scientific, Roskilde Site, Denmark), containing $100 \mu$ drops of culture medium. Either fresh or vitrified embryos were in vitro cultured in medium supplemented with EGF ( $\mathrm{n}=100$ and 75$)$ as compared to control medium without supplementation $(\mathrm{n}=100$ and 75$)$, respectively, under mineral oil in $\mathrm{CO}_{2}$ incubator at $38^{\circ} \mathrm{C}, 95 \%$ humidity and $5 \% \mathrm{CO}_{2}$ in air. Embryos were assessed daily to record the developmental competence of embryos in term of formation rate of embryos at blastocyst from morula stage, from blastocyst to expanded blastocyst stage or from expanded to hatched blastocyst throughout 5 days as culture period. 
ORMATION RATE AND CELLULAR COUNT OF BLASTOCYST RABBITS

\section{Cellular count and intrazonal diameter of embryo at blastocyst stage:}

Five intact embryos in case of fresh or vitrified cultured, with or without EGF, were randomly selected on the second day of cultivation (at blastocyst stage) were stained as described earlier by Koruji et al. (2004). Briefly, embryos were incubated in $0.5 \%$ sodium nitrate solution at $37^{\circ} \mathrm{C}$ for $30 \mathrm{~min}$. Then the embryos were removed using a Pasteur pipette, placed on a clean slide and the excess sodium nitrate was removed from the slide. Before drying the embryos, a few fixatives (mixture of acetic acid and methanol, 1: 3 ) were added to the blastocysts. After air drying, the slides were stained with 5\% Giemsa (Sigma, USA) in PBS for $30 \mathrm{~min}$ and washed with distilled water. Nuclei of the blastomeres were count using a light microscope with magnification of $100 x$.

Embryonic intrazonal diameter at blastocyst stage was measured light microscopy and eyepieces.

\section{Statistical analysis}

Data were analyzed by Analysis of Variance (ANOVA) using computer program of SAS (1998). ANOVA was performed after arcsine transformation of original data expressed as proportions. The significant differences among group means were preformed using Duncan Range Test (Duncan, 1955).

\section{RESULTS AND DISCUSSION}

\section{Effect of EGF on in vitro culture of fresh or vitrified rabbit morulae:}

Results shown in Table $(1)$ revealed significant $(\mathrm{P}<0.05)$ effect of adding epidermal growth factor (EGF) in culture medium on formation rate of embryos at blastocyst (BLs), expanded blastocyst (EBLs) and hatched blastocyst (HBLs) stages after culture period of 5 days of fresh or vitrified embryos (at morula stage). The formation rate of BLs, EBLs and HBLs was significantly $(\mathrm{P}<0.05)$ the highest for fresh embryos cultured with EGF (86.00, 94.11 and 88.92\%), moderate for fresh embryos without EGF (74.00, 81.11 and $75.23 \%$ ) or those vitrified with EGF (70.62, 80.67 and $73.89 \%$ ), and the lowest for vitrified embryos cultured without EGF (57.76, 70.00 and $56.76 \%$ ).

It is interesting to observe that formation rate into all blastocyst stages was higher for fresh than vitrified embryos, regardless EGF addition. In accordance with the present results, Chrenek et al. (2014) showed that after cryostorage and de-vitrification almost $73 \%$ of rabbit embryos survived and developed to advanced blastocyst stage versus $96 \%$ in the intact control. Also, Chrenek and Makarevich (2011) reported significantly lower developmental rate of vitrified/thawed transgenic embryos reached hatching blastocyst stage (68\%) 
Table (1): Formation rate of fresh or vitrified rabbit morula into blastocyst stages in culture medium with or without EGF.

\begin{tabular}{|c|c|c|c|c|c|}
\hline \multirow[b]{2}{*}{ Group } & \multirow[b]{2}{*}{$\begin{array}{c}\text { Treatment } \\
\text { Groups }\end{array}$} & \multirow[b]{2}{*}{$\begin{array}{l}\text { Vitrified } \\
\text { embryos }\end{array}$} & \multicolumn{3}{|c|}{ Development rate } \\
\hline & & & Blastocyst & $\begin{array}{l}\text { Expanded } \\
\text { Blastocyst }\end{array}$ & $\begin{array}{l}\text { Hatching } \\
\text { Blastocyst }\end{array}$ \\
\hline \multirow{2}{*}{$\begin{array}{c}\text { Fresh } \\
\text { morulae }\end{array}$} & Without EGF & 100 & $74.00 \pm 1.87^{\mathrm{b}}$ & $81.11 \pm 1.23^{\mathrm{b}}$ & $75.23 \pm 5.17^{b}$ \\
\hline & Witl & 10 & $86.00 \pm 1.87^{\mathrm{a}}$ & $94.11 \pm 1.86^{\mathrm{a}}$ & $88.92 \pm 1.16^{\mathrm{a}}$ \\
\hline \multirow{2}{*}{$\begin{array}{l}\text { Vitrified } \\
\text { morulae }\end{array}$} & With & 75 & 57.76 & $70.00 \pm 4.45^{\mathrm{b}}$ & $56.76 \pm 3.16^{\mathrm{c}}$ \\
\hline & With EGF & 75 & $70.62 \pm 2.58^{\mathrm{b}}$ & $80.67 \pm 6.09^{b}$ & $73.89 \pm 4.38^{\mathrm{b}}$ \\
\hline
\end{tabular}

Means denoted within the same column with different superscripts are significantly different at $\mathrm{P}<0.05$.

than the control embryos (100\%). In the same line, Makarevich et al. (2008) showed significantly lower ability $(\mathrm{P}<0.05)$ of hatching blastocyst formation when intact (97.0\%) were compared with vitrified rabbit embryos (63\%).

After fertilization, the one cell egg undergoes a series of cleavage divisions, progressing through 2-cell, 4-cell, 8-cell, 16-cell, mulberryshaped 20- to 30-cell mass (morula) to the formation of blastocyst, which is composed of trophoblast and inner cell mass that eventually develop into placenta and embryo, respectively. Accumulated evidence suggests that growth factors are necessary components in early embryonic development in vitro and in vivo (Park and Han, 2009). Successful development of embryo is dependent on genomic expression, regulatory hormone, energy source and growth factors and cytokines secreted from uterine tube, uterus and embryo itself (Kim et al., 1999).

According to the present results, adding EGF enhanced formation rate into all blastocyst stages in rabbits, regardless cryopreservation. In this respect, Koruji et al. (2004) concluded that the higher dose of EGF (10 $\mathrm{ng} / \mathrm{ml}$ ) can improve the development rate of mouse morula. Also in mouse, Głąbowski et al. (2005) found a higher blastocyst rates as well as an augmented uptake of nutrients by blastocyst cells in the media enriched with EGF. The present results and findings previously reported indicated that EGF plays an important role in embryo developmental form as early as preimplantation (Dadi et al., 2007). Finally, EGF has been shown to promote pre-implantation embryo growth (Grazul-Bilska et al., 2003), as well as trophoblast invasion and post implantation embryo growth (Haimovici and Anderson, 1993).

\section{Effect of EGF on cellular contents and intrazonal diameter of cultured blastocysts:}

Results presented in Table (2) cleared that adding EGF in culture medium significantly $(\mathrm{P}<0.05)$ increased average cell number and intrazonal 
ORMATION RATE AND CELLULAR COUNT OF BLASTOCYST RABBITS 261

Table (2): Developmental rate of rabbit embryos fresh or vitrified at morula stages and quality of rabbit embryo in culture media with or without EGF.

\begin{tabular}{|c|l|c|c|}
\hline \multirow{2}{*}{ Group } & \multirow{2}{*}{$\begin{array}{c}\text { Culture } \\
\text { medium }\end{array}$} & \multicolumn{2}{|c|}{ Blastocyst quality } \\
\cline { 3 - 4 } & Total cell number & Intrazonal diameter $(\boldsymbol{\mu m})$ \\
\hline \multirow{2}{*}{$\begin{array}{c}\text { Fresh } \\
\text { morulae }\end{array}$} & Without EGF & $109.00 \pm 2.92^{\mathrm{b}}$ & $124.2 \pm 1.3^{\mathrm{b}}$ \\
\cline { 2 - 4 } & With EGF & $121.20 \pm 2.99^{\mathrm{a}}$ & $129.2 \pm 1.24^{\mathrm{a}}$ \\
\hline $\begin{array}{c}\text { Vitrified } \\
\text { morulae }\end{array}$ & Without EGF & $105.00 \pm 2.74^{\mathrm{b}}$ & $117.6 \pm 0.8^{\mathrm{c}}$ \\
\cline { 2 - 4 } & With EGF & $118.20 \pm 2.03^{\mathrm{a}}$ & $124.6 \pm 0.6^{\mathrm{b}}$ \\
\hline
\end{tabular}

Means denoted within the same column with different superscripts are significantly different at $\mathrm{P}<0.05$.

diameter of blastocysts produced from fresh (121.20/BLs and 129.2 $\mu \mathrm{m})$ or vitrified (118.2/BLs and $124.6 \mu \mathrm{m})$ morulae as compared to fresh $(109.0 / \mathrm{BLs}$ and $124.2 \mu \mathrm{m})$ or vitrified $(105 / \mathrm{BLs}$ and $117.6 \mu \mathrm{m})$ morulae cultured with free media. However, impact of EGF addition was pronounced on intrazonal diameter more than on average cell number of BLs. Such finding may be attributed to increasing cell volume or interstitial space in-between.

It is worthy noting that average cell number and intrazonal diameter of blastocysts produced from fresh morulae was higher than those of vitrified ones, regardless EGF supplementation.

The observed increase in fresh in comparing vitrified morulae regarding cellular number was indicated by Chrenek et al. (2014), who showed that total cell number in the vitrified embryos was significantly lower than in the intact control (117 vs. 135), but they found no significant differences between the vitrified and intact embryos in the embryo diameter (123.2 vs. $129.85 \mu \mathrm{m}$ ). Also, Chrenek et al. (2011) showed that vitrification procedure caused decrease in total cell numbers of vitrified embryos compared to the control group (117 vs. 141/BLs).

In association with the obtained results, Głąbowski et al., (2005) stated that the culture media enriched with EGF showed an accelerated growth, improved blastocoel formation, trophoectoderm expansion and protein metabolism. Also, Koruji et al. (2004) showed significant impact of EGF on cell number of BLs from fresh embryos ( 97 vs. 72.5/BLs, $\mathrm{P}<0.01$ ), but insignificantly affect cell number of BLs from vitrified embryos (79 vs. 72/BLs).

In general, EGF treatment significantly increased the total blastocyst cell numbers compared with the control group due to increases in the numbers of inner cell mass (Zeng and Harris, 2014 and Lee et al., 2005). 
In the embryos, the cryoprotectant comes out gradually from the embryonic cells and so makes the environment unappreciated for embryo development. The beneficial effect of EGF addition to culture medium may induce some biochemical changes especially for vitrified embryos (Koruji et al., 2004).

Conclusively, supplementation of culture medium with $10 \mathrm{ng} / \mathrm{ml}$ epidermal growth factor (EGF) had beneficial effects of the developmental competence of embryos at morula stage to reach hatched blastocyst stage with good quality in terms of higher cellular number and intrazonal diameter. Also, EGF addition is essential tool for reaching higher formation rate of embryos at hatched blastocyst, particularly for cultured vitrified embryos.

\section{REFERENCES}

Ahumada, C. J., Salvador, I., Cebrian-Serrano, A., Lopera, R. and Silvestre, M. A. (2013). Effect of supplementation of different growth factors in embryo culture medium with a small number of bovine embryos on in vitro embryo development and quality. Animal, 7(3): 455462.

Almiñana, C. and Cuello, C. (2015). What is new in the cryopreservation of embryos? Anim. Reprod., 12 (3):418-427.

Arav, A. (2014). Cryopreservation of oocytes and embryos. Theriogenology, 81:96-102.

Babitha, V., Yadav, V.P., Chouhan, V.S., Hyder, I., Dangi, S.S. and Gupta, M. (2014). Luteinizing hormone, insulin like growth factor-1, and epidermal growth factor stimulate vascular endothelial growth factor production in cultured bubaline granulosa cells. Gen Comp. Endocrinol., 198:1-12.

Bagusi, A., Lonergan, P., Overstrom, E. and Boland. M. (2000). Vitrification of bovine embryos: incidence of necrosis and apoptosis. Theriogenology, 51:162.

Celestinos, M. and Gatica, R. (2008). In vitro viability of split rabbit embryos before and after vitrification. 9th World Rabbit Congress - June 10-13, Verona - Italy,

Chandra, V., Misha, A. and Taru, S.G. (2012). Effect of growth factors (epidermal growth factor, platelet derived growth factor, and insulin-like growth factor-1) on buffalo (Bubalus bubalis) embryos produced in vitro. Indian J. Anim. Sci., 82:1510-1514. 
ORMATION RATE AND CELLULAR COUNT OF BLASTOCYST RABBITS 263

Chrenek, P., Makarevich, A. V. and Kubovièová, E. (2014). Developmental potential of vitrified rabbit embryos. Slovak J. Anim. Sci., 47(4): 198-201.

Chrenek, P., Bauer, M. and Makarevich, A. (2011). Quality of transgenic rabbit embryos with different EGFP gene constructs. Zygote, Vol. 19 (1), p. 85-90.

Chrenek, P. and Makarevich, A.V. (2011). Analysis of transgenic rabbit vitrified embryos carrying EGFP gene. Slovak J. Anim. Sci., 44 (1): 1-5.

Cseh, S., Horlacher, W., Brem, G., Corselli, J., Seregi, J. and Solti, L.(1999). Vitrification of mouse embryos in two cryoprotectant solutions. Theriogenology, 52: 103-13.

Dadi, T.D., Li, M.W. and Lloyd, K.C. (2007). EGF and TGF-alpha supplementation enhances development of cloned mouse embryos. Cloning Stem Cells; 9: 315-326.

Díaz-Cueto, L., Gerton, G.L. (2001). The influence of growth factors on the development of preimplantation mammalian embryos. Arch Med. Res., 32:619-626.

Do, V.H., Walton, S. and Taylor-Robinson, A.W.(2014). Benefits and Constraints of Vitrification Technologies for Cryopreservation of Bovine In Vitro Fertilized Embryos. J. Vet. Sci. Anim. Husb., 2(4): 401- 405.

Duncan, D.B. (1955). Multiple range and Multiple F test. Biometrics, 11:1-42.

Fujihara, M., Comizzoli, P., Keefer, C.L., Wildt, D.E. and Songsasen, N.(2014). Epidermal growth factor (EGF) sustains in vitro primordial follicle viability by enhancing stromal cell proliferation via MAPK and PI3K pathways in the prepubertal, but not adult, cat ovary. See comment in Pub. Med. Commons Below Biol. Reprod., 25; 90(4):86.

Gląbowski, W., Rafal, K., Barbara, W., Tomasz, B., Mariola, M. and Pawel, B.(2005).Growth factors effects on preimplantation development of mouse embryos exposed to tumor necrosis factor alpha. Biology of Reproduction, Vol. 5, No. 1.83-99.

Grazul-Bilska, A.T., Choi, J.T., Bilski, J.J., Weigl, R.M., Kirsch, J.D. and Kraft, K.C. (2003). Effects of epidermal growth factor on early embryonic development after in vitro fertilization of oocytes collected from ewes treated with follicle stimulating hormone. Theriogenology, 59:1449-57.

Haimovici, F. and Anderson, D.J. (1993). Effects of growth factors and growth factor-extracellular matrix interactions on mouse trophoblast outgrowth in vitro. Biol. Reprod., 49:124-30.

Kane, M.T., Morgan, P.M. and Coonan, C. (1997). Peptide growth factors and preimplantation development. Human Reproduction Update, 3: 137-157. 
Kim, C.H., Chae, H.D., Chean, Y.P., Kang, B.M., Chang, Y.S. and Mok, J.E. (1999). The effect of epidermal growth factor on the preimplantation development, implantation and its receptor expression in mouse embryos. J. Obstet. Gynaecol. Res., 25: 87-93.

Koruji, S. M., Mansoureh, M. and Mojtaba, R. V. (2004). Assessment of Epidermal Growth Factor (EGF) Effects on Development of Vitrified Mouse Morulae to the Blastocyst Stage. Iranian Biomedical Journal , 8 (2): 77-82.

Lee, G. S., Kim, H.S., Hyun, S. H., Jeon, H.Y., Nam, D.H., Jeong, Y. W., Kim, S., Kim, J. H., Kang, S. K., Lee, B.C. and Hwang, W.S. (2005). Effect of epidermal growth factor in preimplantation development of porcine cloned embryos.Mol.Reprod.Dev.,71: 45-51.

Liu, J., Phy, E. and Yeomans, E. (2012). Theoric considerations regarding slow cooling and vitrification during cryopreservation. Theriogenology, 78:1641- 1652.

Makarevich, A. V., Chrenek, P., Olexikova, L., Popelkova, M., Turanova, Z., Ostro, A., Pivko, J. (2008). Post-thaw survival, cell death and actin cytoskeleton in gene-microinjected rabbit embryos after vitrification. Theriogenology, 70: 675-681.

Mehaisen, G. M. K., Saeed, A.M., Gad, A., Abass, A.O ., Arafa, M . and El-Sayed, A.(2015). Antioxidant Capacity of Melatonin on Preimplantation Development of Fresh and Vitrified Rabbit Embryos: Morphological and Molecular Aspects. Plos One, 10(10): e0139814.

Mehaisen, G.M.K., Viudes-de-Castro, M.P., Vicente, J.S., Lavara, R. (2006). In vitro and in vivo viability of vitrified and non-vitrified embryos derived from eCG and FSH treatment in rabbit does. Theriogenology, 65: 1279-1291.

Pan,Y., Yan,C., Abdul-Rasheed, B., Honghong, He., Jiangfeng, F., Junfeng, He., Qin, Li ., Kun, Y., Qian, Z. and Sijiu, Yu.(2015). Epidermal growth factor enhances the developmental competence of yak (Bos grunniens) preimplantation embryos by modulating the expression of surviving and HSP70. Livestock Science, 182: 118-124.

Park, J.H. and Han, H.J. (2009). Caveolin-1 plays important role in EGFinduced migration and proliferation of mouse embryonic stem cells: involvement of PI3K/Akt and ERK. Am. J. Physiol. Cell Physiol., 297:C935-C944.

SAS, (2000). SAS Institute Inc. SAS User's Guide, Statistics. Cary, NC.

Zeng, F. and Harris, R.C (2014). Epidermal growth factor, from gene organization to bedside. Seminars in Cell \& Developmental Biology, 28: $2-11$. 


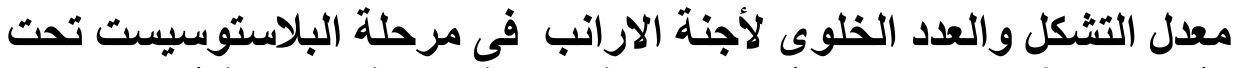

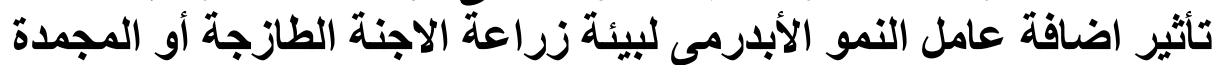 بالتزجج فى مرحلة الموريولا لونة الابنة}

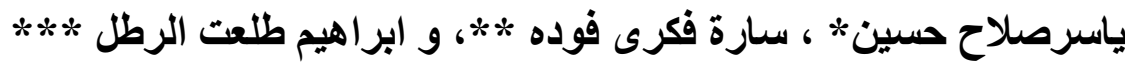

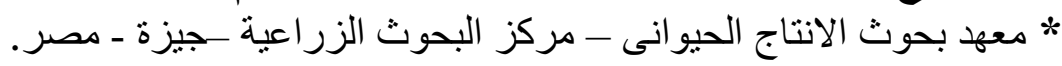

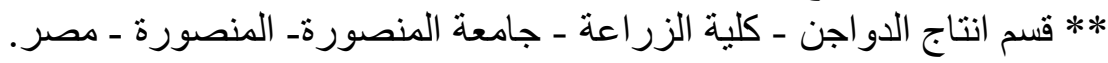

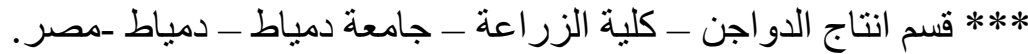

تهذف هذه الدراسة الى تقييم تأثنير اضافة عامل النمو الابدرمى لبيئة زراعة اجنة

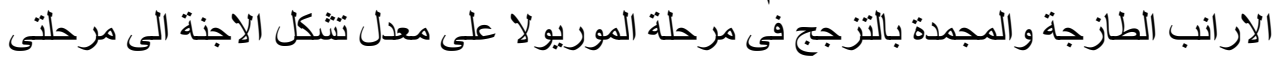

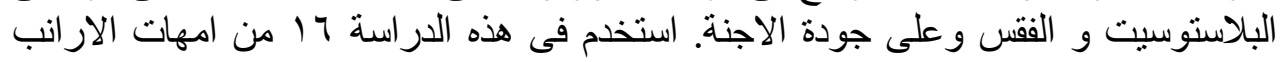

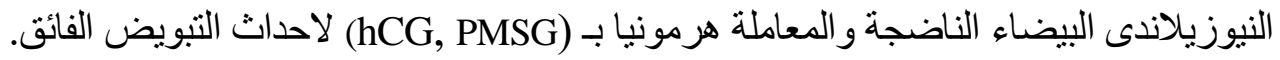

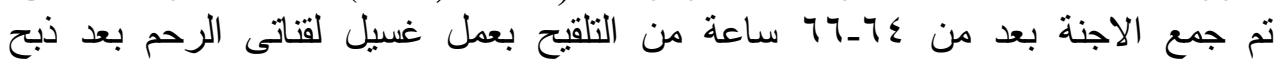

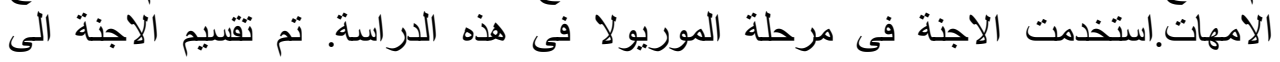

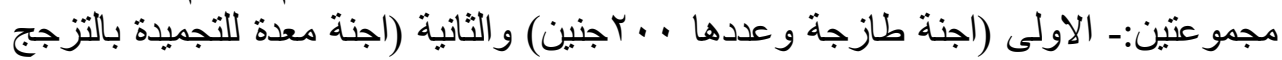

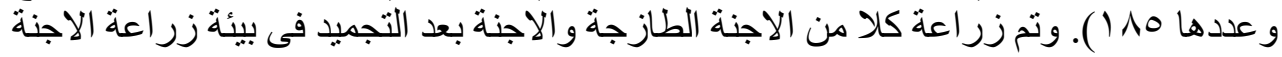

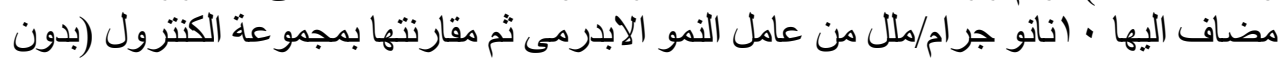

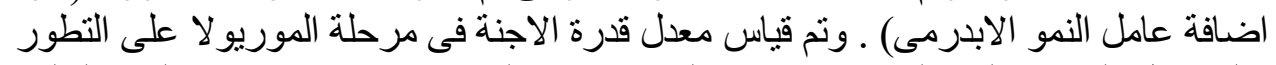

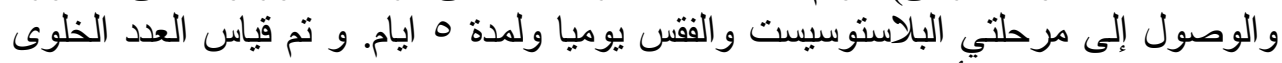
وقطر الزونا الداخلى للأجنة في مرحلة البلاستوسيست

اوضحت النتائج ان معدل تشكل الاجنة فى مراحل البلاستوسيست المختلفة

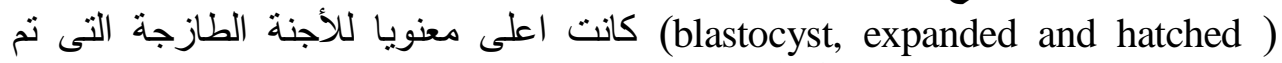

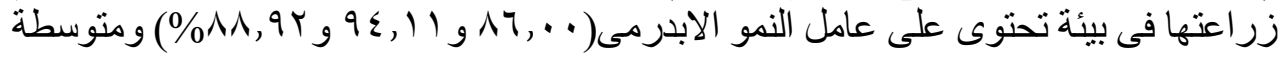

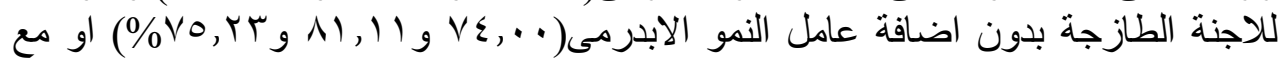

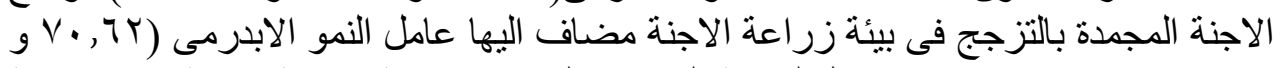

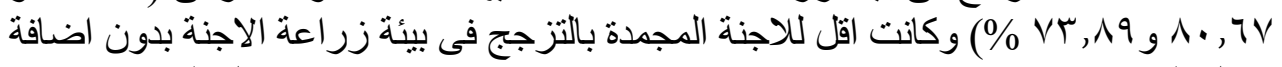

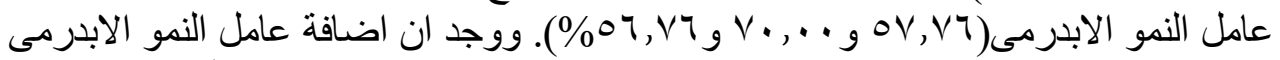

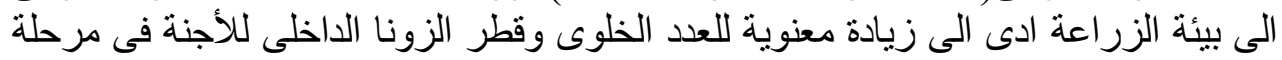

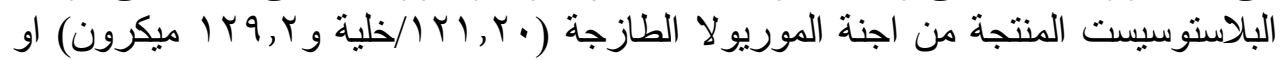

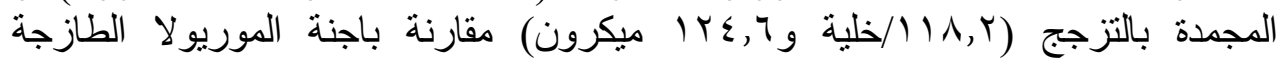

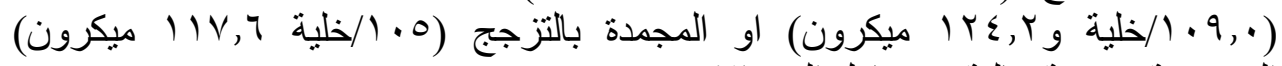

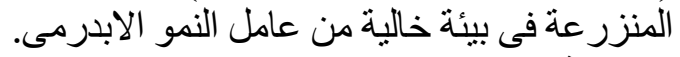

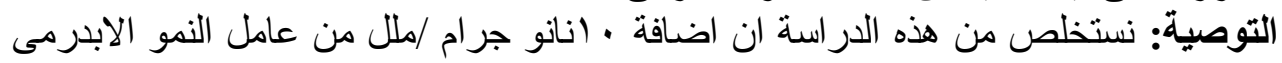

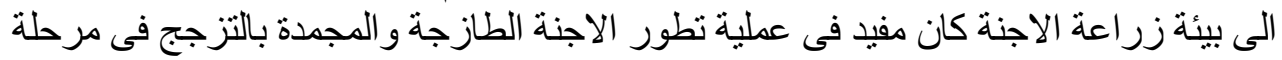
الموريو لا الى مرحلة الفقس مع تحسين جودة الاجنة. 